\title{
Coesão, coerência e pontuação: fatores de textualidade em redações de vestibular
}

\section{TATIANA V. B. Farias}

Mestra em Língua e Literatura Grega pela

Universidade de São Paulo. Professora de língua

latina, grega e portuguesa da Universidade Estácio de Sá.

Resumo: Este trabalho tem por objetivo evidenciar a coesão, coerência e pontuação como fatores de textualidade. Pretende-se verificar em que medida essas características influenciam na construção do texto e até que ponto os usuários da língua têm domínio desses recursos no processo de escrita. A pontuação não costuma aparecer entre os fatores responsáveis pela textualidade, no entanto, não pode ser desconsiderada, uma vez que está embutida nos processos de coesão e de coerência.

Palavras-chave: coesão; coerência; pontuação; textualidade

\section{ValÉRIA MUNIZ}

Doutoranda em Língua Portuguesa pela Universidade Estadual do Rio de Janeiro.

Professora de Língua Portuguesa da Universidade Estácio de Sá.
Abstract: This work wants to evidence the coherence, cohesion and punctuation as text factors. It's intended to show how this characteristics influence the text built and how the native speakers deal with these means in the writing process. The punctuation isn't among the textual qualities, but can't be forget, since it is in the coherence and cohesion process.
Keywords: coherence; cohesion; punctuation; textual qualities 



\section{Introdução}

Este trabalho tem por objetivo evidenciar a coesão, coerência e pontuação como fatores de textualidade. Pretende-se verificar em que medida essas características influenciam na construção do texto e até que ponto os usuários da língua têm domínio desses recursos no processo de escrita. A pontuação não costuma aparecer na lista dos fatores responsáveis pela textualidade. No entanto, não pode ser desconsiderada, uma vez que está embutida nos processos de coesão e de coerência.

A natureza do texto já foi objeto de estudo de muitos teóricos preocupados em desvendar os aspectos relativos a sua produção e recepção. Em sentido amplo, pode-se definir texto como uma "unidade linguística comunicativa básica”. (VAL, 1991, p.3), sem relação de dependência com seu tamanho. Valente (2001, p. 1), citando Halliday e Hassan, define-o como "unidade semântica, não de forma, mas de significado". Ambas as definições fornecem uma ideia precisa da sua natureza.

Koch (2002, p.17) delineia uma conceituação sob outro ponto de vista, no qual a definição de texto está diretamente atrelada à concepção que se tem de língua e sujeito. Para tanto, estabelece três proposições. Na primeira, se a língua for vista como representação do pensamento e o sujeito for "dono do seu discurso", o texto será um produto do pensamento, cabendo ao leitor apenas captar as intenções, num papel passivo. Na segunda, se a língua for vista como instrumento de comunicação e o sujeito for determinado pelo sistema, o texto configurará como produto codificado, cabendo ao leitor, também, uma atuação passiva, uma vez que, tendo acesso ao código linguístico, sua tarefa resume-se a decifrá-lo. E, na terceira, se a língua for vista como atividade interativa e os sujeitos como atores participativos dessa atividade, o texto passa a ser considerado como lugar de interação.

Desse modo, ao relacionar essa última proposição com a definição de Costa Val, estabelece-se a importância 
do texto como unidade de linguagem em uso, o que implica sua característica básica - ser unidade semântica, veiculadora de significado - sendo menos relevante sua forma, conforme Valente (2001).

Apesar das diferentes definições de texto, existe um ponto para onde convergem diferentes teorias, a textualidade. Segundo Val (2000, p. 34), esse conceito diz respeito ao "conjunto de características que fazem com que um texto seja um texto e não apenas uma sequência de frases". Alguns estudiosos, como Beaugrande e Dressler, e Isenberg (apud, VAL, 2000, p. 35 e 40), destacam entre sete a doze procedimentos de textualidade, respectivamente.

$O$ foco de interesse, como se pode perceber, situa-se na dimensão do texto como um todo, ganhando relevância aspectos como coesão, responsável pela conexão entre enunciados, e a coerência, pela lógica subjacente representante do significado do texto. Considerandose a coesão e coerência como fatores de textualidade, destacam-se as palavras da autora, que defende a tese que essas duas características não estão no texto, pois são processadas no decorrer da leitura.

De acordo com a autora, são vãs as indagações sobre o fato de um texto "ter ou não coerência, ter ou não coesão" (idem, p.48). Conforme esse ponto de vista, poder-se-ia afirmar que não há textos incoerentes, uma vez que o leitor sempre buscará dotá-lo de sentido, partindo do pressuposto de que há ali uma intenção comunicativa. Segundo ela, se alguém "interpreta um artefato como texto, é porque conseguiu aplicar a ele alguns dos princípios da textualidade, construindo sua coesão, sua coerência e tudo mais".(Idem, p.48).

Apesar de reconhecer a pertinência dessa afirmação, como podemos analisar os textos em que a interpretação se processa de modo fragmentário, em que o leitor, ao término da leitura, fica apenas com uma vaga noção do que leu? Será que, mesmo assim, poder-se-ia 
falar em coerência? Ou, partindo-se para outro extremo, seria o caso de um não-texto?

Koch (2002) também afirma que a coerência não é uma qualidade imanente ao texto, mas não entra no mérito da questão sobre um texto poder ou não ser considerado incoerente. Sua atenção está voltada para o aspecto teórico e não didático. De acordo com essa ótica, o leitor ativa seu conhecimento de mundo, no decorrer da leitura, de modo a atribuir significado aos elementos linguísticos, constituindo para aquele objeto uma unidade semântica, detentora de sentido para ele. Nessa perspectiva, a interpretação não é realizada apenas a partir do conhecimento da língua, mas também em razão da cultura de cada um. Assim, podem existir ocasiões em que as informações não são processadas, devido à ausência de conhecimento proveniente de leituras anteriores, ou seja, não há como se estabelecer relações com uma base inexistente. Nesse caso, não é o texto incoerente em si mesmo, mas o será para essa pessoa, nessa situação. Porém, haverá situações, conforme já colocado, em que a interpretação é dificultada não pela ausência de informações, mas por problemas contidos na estrutura.

Contribuindo com a coerência na constituição do texto, estão os mecanismos coesivos responsáveis pelas relações de sentido entre suas partes. Segundo Val (1991, p. 6), a coesão é "a manifestação linguística da coerência". Por intermédio dos recursos gramaticais e lexicais, os nexos coesivos auxiliam na composição da microestrutura do texto contribuindo para sua unidade. Apesar dessa relação imbricada entre coesão e coerência, as duas constituem fenômenos distintos (não na concepção de Michel Charolles, como será visto mais adiante), o que pode ser compreendido pelo fato de existirem textos que dispensam elementos coesivos. Todavia não há dúvida de que esse recurso configura um facilitador na articulação das idéias, favorecendo sua progressão e continuidade.

No próximo caso, apesar da ausência dos elementos de coesão, a inteligibilidade do texto não é afetada. A 
coerência é alcançada por intermédio do campo semântico que, ao ordenar hierarquicamente as palavras, favorece sua unidade. "Manhã, banho, café, ônibus, trabalho, obrigações, almoço, obrigações, ufa!, ônibus, casa, noite, banho, janta, televisão, cama!!!"

Há situações em que parece não haver coesão. No entanto, ela está camuflada, conforme acontece no poema de José Paulo Paes, intitulado "A moda da casa”. (VALENTE, 2001, p. 14). Nesse poema, os sufixos se configuram, enquanto recurso fonológico, como elementos coesivos. Segundo classificação de Fávero, seria o caso de "coesão recorrencial" (2001, p.26). "Feijoada/ Marmelada/ Goleada/ Quartelada."

Val (1991, p. 7) opunha-se ao fato de um texto poder dispensar os "nexos", considerados por ela como relativos à "coerência (ligação entre conceitos) ou à coesão (expressão da coerência no plano linguístico)". De acordo com essa autora, esse nexo sempre existiria, mesmo que não estivesse explícito na superfície do texto por intermédio de um mecanismo gramatical. Para endossar seu ponto de vista, utilizou o seguinte exemplo: "Pedro vai buscar bebidas. A Sandra tem que ficar com os meninos. A Tereza arruma a casa. Hoje eu vou precisar de todo mundo". (Idem, p. 17). Nessa sequência, de fato, os elementos gramaticais estão implícitos, o que pode ser verificado se o mesmo trecho for lido de outra forma: "Enquanto Pedro busca as bebidas, a Sandra fica com os meninos e a Tereza arruma a casa." Há uma relação temporal entre os fatos que remetem de forma explicativa à oração absoluta: "Hoje eu vou precisar da ajuda de todo mundo.” Na leitura de Fávero (2001, p.12), "a coerência não deve ser buscada unicamente na sucessão linear dos enunciados (ela não é unidimensional), mas, sim, numa ordenação hierárquica (é pluridimensional)". Assim, a última oração, por ser mais abrangente, recupera a unidade, fazendo a ligação com as frases anteriores.

Mais tarde, Val redefine seu posicionamento em relação à coesão. De acordo com suas reflexões, a coesão, 
assim como a coerência, não deve ser considerada como uma característica imanente ao texto, na medida em que deverá ser processada pelo usuário no momento da interação. Segundo ela, "a coesão não está lá pronta, mas está apenas sinalizada”. (VAL, 2001, p. 38). Seria interessante entender o que significa para a autora "não estar pronta, mas sinalizada". De acordo com o exemplo dado por ela em seu livro (fato analisado no parágrafo anterior), acredita-se, assim como a autora, que a coesão esteja apenas sinalizada. Mas, na maior parte dos casos, em que os nexos coesivos estão materialmente presentes, concebe-se a coesão, pronta. Sem dúvida que a interpretação vai depender da capacidade de o leitor recuperar o dito e o não dito, num processo de interação, mas isso não implica que a relação não esteja explícita linguisticamente. Pode-se, para efeito de ilustração, citar os casos em que o redator utiliza um conectivo inadequado, rompendo com a estrutura da frase, causando estranhamento no leitor. Ainda assim, seria apropriado dizer que a coesão não está lá, "pronta"? A leitura é encaminhada na direção sinalizada pelo operador coesivo. Somente depois de reler o trecho, o sentido será reconstruído, devido ao conhecimento de mundo de quem está lendo. Desse modo, preferiuse adotar, neste trabalho, a concepção de coesão desenvolvida pela autora em seu livro em 1991, (assim como se adotou para a coerência).

Retomando-se a questão de poder haver textos coerentes sem elementos coesivos, verifica-se que também há textos com coesão sem coerência, como ocorre em: "Ele saiu de casa para comprar jornal, quando o quadrado da hipotenusa se disse igual a soma dos catetos." A presença da conjunção "quando", apesar de situar as orações em relação ao tempo, não é suficiente para dotar o enunciado de sentido. Defende-se, então, a coerência como fator imprescindível para a textualidade, funcionando como o último resultado a ser alcançado - a unidade de sentido. 
Contribuindo com a coerência e a coesão, situase a pontuação que participa não só da organização do texto, como de seus sentidos também. Um texto constitui-se enquanto tal, no momento em que "os parceiros de uma atividade comunicativa global, diante de uma manifestação linguística, pela atuação conjunta de uma complexa rede de fatores de ordem situacional, cognitiva, sociocultural e interacional, são capazes de construir, para ela, determinado sentido". (KOCH, 2003, p. 30). Desse modo, leituras serão realizadas de acordo com o conhecimento enciclopédico de cada um, e a pontuação no seu papel demarcativo sintático propicia essa interpretação.

Essa definição de Koch reforça a dimensão pragmática presente no texto em sua recepção, mas poderia ser aplicada ao momento da produção do texto, constituindo o que se chama por dialogismo. De acordo com essa teoria, não se atribui ao sujeito o "ponto zero" do processo criativo. Considera-se que os discursos se entrelaçam, numa rede polifônica, isto é, ao se construir um determinado texto, parte-se de outros textos contidos no contexto cognitivo de cada um.

Essa heterogeneidade enunciativa e o processo interativo constitutivo do texto evidenciam o caráter criativo da língua, a qual propicia "ao indivíduo dispor dela para manifestar sua liberdade de expressão" (BECHARA, 1985, p. 13).

Conforme essa perspectiva, pretende-se abordar a questão da pontuação sob um ponto de vista textualdiscursivo, a fim de percebê-la como modo de atribuição de sentido. Nesse caso, ela manifesta-se como fator de textualidade, relacionando-se às características de coesão e coerência.

A pontuação, entre outras funções, tem o importante papel de imprimir legibilidade ao texto escrito, constituindo-se em marcador gráfico da enunciação. Em que pese essa função lógico-gramatical, 
contida no nível sintático, não se pode desprezar suas características semânticas e enunciativas. Essa qualidade "plurifuncional" (JUNKES, 2002, p. 61) abarca: no nível sintático, a indicação dos limites da frase, numa função demarcativa; no nível enunciativo, a prioridade da intenção comunicativa, ou seja, o sentido a ser alcançado sobrepõe-se em relação à sintaxe; e, no nível semântico, o mais abrangente, a inclusão dos outros dois, por estar associado ao sentido.

Tendo em vista essa tríplice característica, percebese que os sinais gráficos, além de separar e organizar as unidades sintáticas, funcionando como elementos de coesão, configuram-se como um instrumento de produção de sentido, estando atrelados à coerência. Nesse sentido, permitem ao usuário a realização de suas intenções estéticas, atingindo uma função expressiva.

Nota-se, então, a inexistência de uma única leitura, podendo ser os textos marcados por uma carga de conotações, possível somente devido às possibilidades de uso que a língua oferece. Essa falta de unicidade, entretanto, não se traduz em ausência de unidade, pois um texto, para ser considerado texto, necessita que suas palavras componham um todo significativo. E, nesse processo, a pontuação funciona como elemento de continuidade na elaboração do sentido, exercendo um papel intelectivo, estruturante do pensamento, constituindo-se indispensável na ordenação das palavras. Em outras palavras, "quando negligenciada, torna o texto nebuloso e até ambíguo”. (Idem, p. 38).

A pontuação deve ser vista como um dos componentes na organização das ideias. Tão importante quanto a escolha lexical e o uso de conectivos, é o papel dos sinais gráficos na construção do texto, que além da função demarcativa, oferecem a possibilidade ao usuário de optar por um deles em detrimento de outros, consideradas as circunstâncias. Apesar das regras que normatizam a pontuação, o contexto enunciativo influenciará de forma decisiva na organização do texto. Isto é, pode-se subverter 
a regra em prol da expressividade, sobrepondo-se a função semântica por intermédio de operações operadas no nível sintático. Essa base subjetiva deve ser desvelada, pois ao mesmo tempo em que mexe com a estrutura, favorece o processo criativo da escrita.

Esse processo é uma atividade que exige planejamento, envolve escolhas e decisões. O redator precisa estar atento a suas idéias, a hierarquização delas no texto, percebendo a pontuação como sua aliada na organização das palavras para o sentido desejado, não embotando outros a serem alcançados no decorrer da leitura.

Esses sinais gráficos, longe de serem acessórios, são participantes ativos da textualidade, interferindo seja na coesão, seja na coerência. Essa afirmativa respalda-se nas palavras de Bechara, que assim define pontuação: "sistema de reforço da escrita, constituído de sinais sintáticos, destinados a organizar as relações e a proporção das partes do discurso e das pausas orais e escritas". (BECHARA, 1999, p. 64). Esse gramático divide a pontuação entre os sinais essencialmente separadores e os sinais de comunicação ou mensagem, admitindo uma subdivisão em sinais de pausa conclusa e de pausa inconclusa. Segundo ele, "esses sinais não se aplicam igualmente a todas as atividades linguísticas, razão por que podem ser distribuídos em três domínios de função de pontuação: a pontuação de palavras, a pontuação sintática e comunicativa e a pontuação do texto". (Idem, p. 605).

Essas funções vão ao encontro da proposta defendida neste trabalho, que assume a existência de uma relação entre a pontuação e o entendimento do texto, numa clara parceria entre sintaxe e semântica. Nessa perspectiva, os sinais gráficos instauram-se como um expediente integrante de todas as estratégias da escrita, seja imprimindo-lhe um caráter de objetividade, seja fornecendo-lhe outros sentidos, num processo de interação com o interlocutor. 
A concepção de língua como atividade interativa impõe como condicionante sua adequação à circunstância de uso. Isso se reflete na construção do texto em todos os seus aspectos, inclusive na pontuação, pois essa não é algo a ser acrescentado, uma vez que está inserida no próprio processo de escrita. Percebe-se, assim, a relação que se estabelece entre língua e contexto-sociocultural, em que a linguagem alcança valor social, resultando em um entrelace entre falante, uso da língua e prestígio.

Pretende-se, neste trabalho, destacar a contribuição da pontuação como fator de textualidade, evidenciando sua participação na coesão e coerência. Para isso, foram analisadas trinta redações do vestibular da UERJ, das quais serão transcritos apenas alguns trechos com os respectivos comentários de modo a servir ao propósito deste trabalho. Para tanto, será enfocada somente a pontuação.

$1^{\circ}$ caso: parágrafo longo, sem uso de ponto, o que dificulta a leitura. Ao não separar as informações, o produtor do texto passa a contar com a participação do seu leitor em preencher as lacunas e "recuperar" o sentido pretendido. A má utilização da pontuação acarreta um emparelhamento de idéias relacionáveis entre si, mas não articuladas, resultando num parágrafo sem coesão, interferindo no plano da coerência.

(...) Em que pese o exemplo trazido acima não se aplicar a maioria da população mundial, acreditase que a sociedade contemporânea tenha recursos suficientes para fazer o seu próprio controle pessoal de qualidade, já que em exceção de uma minoria de países ainda alijada do processo de globalização mundial, os níveis de educação e desenvolvimento aumentaram consideravelmente nos últimos anos e, como conseqüência, a grande exigência dessa nova comunidade globalizada faz com que haja uma espécie de seleção natural dos programas difundidos nos meios de comunicação, não se justificando qualquer forma de censura. (...) (Red. 6) 
2o caso: frases curtas, compondo uma estrutura fragmentária. Não há infração nesse estilo. Segundo Garcia (1995, p. 108), “se não há necessidade de mostrar a coesão íntima entre as ideias, esse tipo de construção se torna bastante expressivo". O que não ocorre aqui. A fim de cumprir com as exigências da prova, parece que o candidato, para evitar o erro, prefere as frases curtas.

\begin{abstract}
(...) Com a terceira Revolução Industrial, a comunicação tornou-se um meio indispensável no cotidiano do homem. Ela serve para interligar cultura, esporte, informação e negócio no mundo todo. Tem como objetivo facilitar a vida das pessoas. No entanto, há grupos que utilizam esses meios para divulgar pedofilias, preconceitos, facções criminosas ou capitalizar o lazer dos cidadãos. (red. 7 )
\end{abstract}

3o caso: uso do ponto antes de conjunção. Esse tipo de construção produz fragmentos de frase, uma vez que rompe com sua estrutura. Conforme Garcia (1995, p. 118), "o trecho é inanalisável segundo os cânones gramaticais; não obstante, constitui forma de expressão legítima no Português moderno". No parágrafo abaixo, a fragmentação não configura estilo, mas defeito. Se houvesse uma reorganização sintática, o parágrafo poderia ficar mais ordenado.

(...) Logo, é preciso uma fiscalização maior e mais rígida para controlar esse 'mal' que abala a sociedade. E também um incentivo governamental nas empresas para que os privilégios não sejam apenas da elite, mas, sim, de uma grande parcela da população. Porque a comunicação é importante na sociedade, uma vez que ela reúne grupos étnicos diferentes e informa simultaneamente os acontecimentos de todos os lugares. (red. 7) 
4o caso: pontuação estilística. A enumeração de substantivos separados por vírgula deixa transparecer uma intenção do candidato em realçar cada um deles. Não há, entretanto, uma regra que justifique esse uso. "Jornais. Revistas. Rádio. Televisão. Filmes. Internet. Os meios de comunicação vêm crescendo e evoluindo e, além disso, ganham grande importância na sociedade. (...)”. (red.11)

5 caso: após a palavra censura, em sua primeira ocorrência, foi utilizada vírgula no lugar do ponto, não fechando a primeira oração. Se, em vez de retomar censura com o determinante demonstrativo, utilizasse pronome relativo, a frase poderia ser continuada, mas, nesse caso, o período ficaria longo, prejudicando um pouco a sua estruturação. Após o adjetivo "concreta", usou-se novamente a vírgula no lugar do ponto. Essa oração funciona como uma declaração conclusiva em relação ao período anterior e por causa da ausência do conectivo faz-se necessário o uso do ponto. Nesse caso, a melhor solução estaria no uso adequado dos sinais de pontuação.

(...) Durante o período do governo militar, assim como os artistas, a mídia sofreu absurdamente com a censura, essa censura privou a população de tomar conhecimento de informações relevantes, impedindo assim, que a mesma formasse uma opinião concreta, a única verdade que era conhecida era a dos militares.". (redação 9).

6o caso: o segundo período rompe a estrutura do parágrafo, fragmentando-o, devido a ser constituído por oração absoluta. Na verdade, essa oração iniciada por um conectivo causal é oração principal da seguinte: "porque os melhores espetáculos, novelas eram censurados", que funciona como oração adverbial causal. Houve erro tanto na inversão entre causa e consequência, como de pontuação, ao se separar por ponto a oração subordinada da principal. 
(...) Também não podemos só ver o que a sociedade manda, senão estaríamos numa 'caverna da alienação' proposta pela mídia. Como a censura já nos deixou cheios de raiva. $\mathrm{Na}$ época da ditadura os melhores espetáculos, novelas eram censurados, pois criticavam o governo militar e sua tirania. (redação 21).

7o caso: erro ao separar por ponto a oração subordinada adverbial causal: "tendo em vista o grande poder de influência desses meios, e a ganância de que está no poder por mais poder", da sua principal. Ao romper com a estrutura da frase, por falha na pontuação, o leitor é obrigado a recuperar o sentido.

(...) Tendo em vista o grande poder de influência desses meios, e a ganância de que está no poder por mais poder. O controle dos meios de comunicação por uma única instituição, governamental ou não, transformará esses meios em uma máquina de alienação e total ignorância ainda maior. (redação 3).

8o caso: nesse trecho, a frase ficou fragmentada, por romper com sua estrutura. Houve erro ao se separar por ponto a oração principal - "as liberdades conquistadas ao longo de gerações não podem ser afetadas" - da subordinada, não configurando recurso estilístico. “(...) Entretanto, as liberdades conquistadas ao longo de gerações não podem ser afetadas. Visto que o respeito à cultura, aos diferentes gostos e idéias devem ser garantidos." (redação 16).

Resumindo a análise, percebeu-se, em várias redações, a prática do uso de frases curtas emparelhadas, sem conectivo, cujas relações de sentido não se desenvolvem. Segundo Costa Val (1991, p.68), “o único vínculo entre as proposições é a reiteração lexical pura e simples ou a paráfrase". Avalia-se esse procedimento como uma tentativa do candidato em não errar. Em alguns 
casos, porém, apesar de não configurar erro, a construção do texto ficou fragmentada.

Detectou-se, também, uma prática bastante comum do uso de ponto simples antes de conectivos adversativos ou de operadores discursivos. Em alguns casos, esse tipo de pontuação, constituiu forma de expressão; em outros, o resultado não foi positivo, configurando infração.

De maneira geral, pôde-se comprovar uma quantidade muito grande de infrações às regras da pontuação. Não houve, todavia, neste corpus, nenhuma redação que deixasse transparecer que o candidato não sabia pontuar. Entretanto, cabe destacar que o uso dos sinais de pontuação parece situar-se mais no nível da intuição, do que do conhecimento, daí talvez o motivo dos erros ou infrações.

\section{Conclusão}

A textualidade constitui-se na medida em que uma sequência de frases ganha unidade de sentido, podendo ser chamada de texto. Entre os aspectos pertinentes que garantem a construção de um todo significativo, estão a coesão e a coerência. Fazendo parte da primeira e influenciando a segunda, está a pontuação, responsável por separar as partes do discurso, indicando a leitura desejada.

O texto concebido como unidade da língua em uso deixa em evidência seu aspecto interativo. Embora seja importante a participação do outro no processo de leitura, uma vez que o sentido não é imanente ao texto, cumpre destacar que a sua colaboração não deve ser a de preencher lacunas. Apesar da existência do Princípio da Cooperação, proposto por Grice (apud, MAINGUENEAU, 2004, p.31), não se pode fazer do leitor um co-produtor.

A incapacidade de operar adequadamente elementos coesivos por meio do sistema léxico-gramatical da língua demonstra a importância discursivo-textual das classes gramaticais, no caso em questão, dos operadores lógicos e 
discursivos. Esses contribuem com a estruturação do texto, na linha argumentativa, ao estabelecerem na superfície linguística, por meio de expedientes gramaticais, relações de sentido que ultrapassam as palavras em si mesmas.

O grau de textualidade de uma redação será determinado pela coerência (VAL, 1991, p. 128) e, para isso, fatores como a coesão e a pontuação são decisivos, sem desconsiderar, todavia, os outros cinco fatores apontados por Beaugrande e Dressler (apud VAL, 1991, p. 5). Desse modo, destaca-se a importância da produção de textos na escola, como um dos meios mais eficazes para se atingir a competência textual. Não basta escrever, é fundamental a reescritura, a análise do próprio texto, a fim de trabalhar o olhar crítico, que possibilite ao redator perceber as inadequações ou erros resultantes de determinada organização.

Várias redações do corpus selecionado apresentaram deficiências de toda ordem, mas ressaltam-se em praticamente todas elas erros provenientes de pontuação, uso inadequado de conectivos ou operadores discursivos, afetando a coerência do texto. Não se pode deixar de mencionar aquelas certinhas, que cumpriram o esperado, mas que nem por isso foram consideradas melhores, devido à argumentação fraca, e, mesmo, ao nível de informatividade. Quanto aos erros ortográficos, a incidência foi bem pequena, sendo poucos os casos absurdos.

Não se pode afirmar nada sobre o nível dos estudantes, pois não se teve acesso aos questionários socioeconômicos, mesmo assim, isso não invalida a pesquisa, uma vez que, por ser uma universidade pública, o exame deve abranger uma clientela bem diversificada. E, como, de maneira geral, não houve discrepâncias entre as redações que pudessem levar à pressuposição de estudantes oriundos da rede de ensino particular ou pública, acredita-se que o problema em torno da pontuação, dos mecanismos coesivos e da coerência não é privilégio de alunos que possam ser identificados como pertencentes a determinado tipo de escola. 


\section{Referências}

BECHARA, Evanildo. Moderna gramática portuguesa. 37. ed. Rio de Janeiro: Lucerna, 1999.

BECHARA, Evanildo. Ensino da Gramática. Opressão? Liberdade? São Paulo: Ática, 1985.

CHAROLLES, Michel. Introdução aos problemas da coerência dos textos. In: ORLANDI, Eni Pulcinelli (org.) et al. O texto: leitura e escrita. São Paulo: Pontes, 1988.

FÁVERO. Leonor Lopes. Coesão e coerência textuais. 9. ed. São Paulo: Ática, 2001.

GARCIA, Othon, M. Comunicação em prosa moderna. 16. ed. Rio de Janeiro: Fundação Getúlio Vargas, 1995.

GUIMARÃES, Elisa. Sintaxe e coesão no texto. In: VALENTE, André (org.). Aulas de Português. Petrópolis, RJ: Vozes, 1999.

JUNKES, Terezinha Kuhn. Pontuação: uma abordagem para a prática. Florianópolis: UFSC, 2002.

KOCH, Ingedore. G. Villaça. Desvendando os segredos do texto. 2. ed. São Paulo: Cortez, 2002.

KOCH, Ingedore. G. Villaça. O texto e a construção dos sentidos. 7. ed. São Paulo: Contexto, 2003.

MAINGUENEAU, Dominique. Análise de textos de comunicação. São Paulo: Cortez, 2004.

VAL, Maria da Graça Costa. Redação e textualidade. São Paulo: Martins Fontes, 1991. 
VAL, Maria da Graça Costa. Repensando a textualidade. In: AZEREDO, Carlos de (org.). Língua portuguesa em debate. Petrópolis, RJ: Vozes, 2000.

VALENTE, André. Coesão e coerência em textos jornalísticos. Rio de Janeiro, Revista v. 6, no 16, p. 5 a 23, 2001. 